Entretextos

Entretextos 21(1): jan./jun. 2021

ISSN 1519-5392 UEL

DOI: $10.5433 / 1519-5392.2021 v 21 n 1 . p .5$

\title{
Ponto e vírgula em desuso? Estudo sobre o uso do ponto e vírgula em textos midiáticos contemporâneos
}

\author{
Semicolon in disuse? Study on the use of semicolons in contemporary \\ media texts
}

\begin{abstract}
Punto y coma en desuso? Estudio sobre el uso de punto y coma en textos mediáticos contemporáneos
\end{abstract}

\author{
Milenne Biasotto* (iDhttp://orcid.org/0000-0002-7729-6845 \\ Eliziete Chaves da Costa* (1) http://orcid.org/0000-0001-7450-7806
}

\begin{abstract}
RESUMO: Neste trabalho, propusemos a investigação da hipótese de que o ponto e vírgula encontra-se em desuso na língua portuguesa. Esta hipótese foi aventada a partir da observação de textos escritos por acadêmicos de um curso de Letras, nos quais notamos que este tipo de pontuação é praticamente inexistente. Diante dessa constatação, procuramos investigar, em uma mídia escrita de grande circulação nacional, a confirmação da hipótese. Foram selecionados 24 textos jornalísticos escritos por 4 colunistas do jornal, com o intuito de realizar um levantamento quantitativo das ocorrências do ponto e vírgula. Previamente, realizamos um estudo bibliográfico para evidenciar as funções prescritas por gramáticas normativas para o uso do ponto e vírgula, elaborando um rol desses usos. Em seguida, verificamos, nas ocorrências encontradas nos textos jornalísticos, quais dos usos arrolados nas gramáticas ocorreram com maior frequência. A análise dos dados aponta que o ponto e vírgula ainda não se encontra em desuso, sendo produtivo ao menos na esfera comunicativa investigada. Além disso, foi possível verificar que as prescrições gramaticais sobre esse tipo de pontuação são vagas e imprecisas. A partir desta pesquisa, pretendemos contribuir com os estudos sobre a pontuação, propiciando reflexões que possam enriquecer a área e fornecer material para consulta.
\end{abstract}

PALAVRAS-CHAVE: Escrita. Pontuação. Textos midiáticos. Ponto e vírgula.

ABSTRACT: In this work we proposed the investigation of the hypothesis that the semicolon is in disuse in Portuguese language. This hypothesis was raised from the observation of texts written by university students of a course of Letters, in which we noticed this type of punctuation is practically non-existent. Considering this, we seek to investigate, in a newspaper of great circulation, if the hypothesis raised was confirmed. We selected 24 journalistic texts written by 4 columnists, in order to perform a quantitative survey of occurrences of semicolons. Previously, we conducted a bibliographical study to highlight the functions prescribed by normative grammars for the use of semicolons, elaborating a list of these uses. Subsequently, we verified, in the occurrences found, which of the uses enrolled in the grammars occurred more frequently. The

\footnotetext{
* Doutora em Linguística e Língua Portuguesa e Professora Adjunta na Universidade Federal da Grande Dourados (UFGD). E-mail: milennebiasotto@ufgd.edu.br

* Graduanda em Letras na Universidade Federal da Grande Dourados (UFGD). E-mail: elizevandy@hotmail.com
} 
data analysis points out that semicolon is not yet in disuse, being productive at least in the communicative sphere investigated. Moreover, it was possible to verify that grammar prescriptions about this type of punctuation are vague and innacurate. With this research, we intend to contribute with the studies about the punctuation, which, in Brazil, are very scarce, providing reflections that can enrich the area and provide material for consultation.

KEYWORDS: Written. Punctuation. Media texts. Semicolon.

RESUMEN: En este trabajo, investigamos la hipótesis de que el punto y coma está en desuso en portugués. Esta hipótesis fue sugerida a partir de la observación de textos redactados por académicos de un curso de Letras, en el cual notamos que este tipo de puntuación es prácticamente inexistente. Así, tratamos de investigar, en un periódico nacional, si se confirmaba la hipótesis. Se seleccionaron 24 textos periodísticos, escritos por 4 columnistas, para llevar a cabo una encuesta cuantitativa de las ocurrencias del punto y coma. Anteriormente, realizamos un estudio bibliográfico para resaltar las funciones prescritas por las gramáticas normativas para el uso de punto y coma, elaborando una lista de estos usos. Luego, verificamos, en las ocurrencias encontradas en los textos periodísticos, cuál de los usos enumerados en las gramáticas ocurrió con mayor frecuencia. El análisis de datos señala que el punto y coma todavía no está en desuso, siendo productivo al menos en la esfera comunicativa investigada. Además, fue posible verificar que las prescripciones gramaticales sobre este tipo de puntuación son vagas e imprecisas. Con esta investigación, pretendemos de contribuir a los estudios sobre la puntuación, proporcionando reflexiones que puedan enriquecer el área y aportar material de consulta.

PALABRAS CLAVE: Escritura. Puntuación. Textos mediáticos. Punto y coma.

\section{Introdução}

Contemporaneamente, o uso da pontuação é visto como essencial para a escrita de qualquer tipo de texto. Tanto sua ausência quanto seu uso inadequado certamente prejudicam a construção dos sentidos que se deseja atribuir aos textos.

A proposta desta pesquisa visa contribuir com os estudos sobre a pontuação no Brasil, fornecendo dados que possam auxiliar na compreensão desse fenômeno, bem como no seu ensino.

O interesse pela questão surgiu a partir da observação de textos de alunos do curso de Letras da Universidade federal da Grande Dourados - UFGD, no qual uma das pesquisadoras atua como docente. Em dois momentos do curso em que os alunos escrevem textos, solicitados pela docente ${ }^{1}$, é possível verificar que há sérias dificuldades quanto aos usos da pontuação (BIASOTTO; BUTTINI, 2018), em especial, a vírgula e o

\footnotetext{
${ }^{1}$ No $1^{\circ}$ semestre do curso, na disciplina Escrita e Ensino, e no $7^{\circ}$ e $8^{\circ}$ semestres, nos componentes curriculares de Estágio Supervisionado em Língua Portuguesa I e II. É bastante relevante destacar que a análise dos textos escritos pelos alunos do curso de Letras tem sido realizada pela docente desde 2014, o que, numericamente, pode ser traduzido em mais de 2000 textos observados.
} 
ponto final. Nas verificações realizadas nos textos, um outro fato chamou a atenção: o ponto e vírgula era praticamente inexistente nos textos dos acadêmicos.

A partir dessa constatação, originaram-se alguns questionamentos que nortearam esta pesquisa: o ponto e vírgula encontra-se em desuso na língua portuguesa? Ou apenas os escritores menos experientes não lançam mão desse recurso na escrita? Qual é a função do ponto e vírgula de acordo com gramáticas normativas? O tratamento dado pelas gramáticas auxilia na compreensão do fenômeno?

Buscando responder a estas questões, este artigo se organiza em quatro partes, além da introdução e considerações finais. Na primeira parte, buscamos o entendimento da função da pontuação em gramáticas normativas da língua portuguesa. Em seguida, procuramos demonstrar a dificuldade de tratamento da pontuação tendo em vista os posicionamentos divergentes acerca de sua função. Na parte seguinte, elencamos os usos do ponto e vírgula de acordo com algumas gramáticas normativas e, finalmente, verificamos, em textos midiáticos contemporâneos, as ocorrências dessa pontuação, bem como as funções que mais ocorreram.

\section{A função da pontuação}

Se analisarmos algumas gramáticas normativas da língua portuguesa, perceberemos que a função atribuída à pontuação é relacionada, muitas vezes, à oralidade. A esse respeito, convém trazer a posição de alguns estudiosos da língua portuguesa.

Terra (2011, p. 319), na obra Curso Prático de Gramática 2, defende que "[...] alguns sinais de pontuação servem, fundamentalmente, para marcas pausas (o ponto, a vírgula, o ponto e vírgula); outros têm a função de marcar a melodia, a entonação da fala (ponto de exclamação, ponto de interrogação etc.)".

A respeito da pontuação, Lima (2001, p. 458), na Gramática Normativa da Língua Portuguesa, afirma:

As pausas rítmicas, - assinaladas na pronúncia por entoações características e na escrita por sinais especiais - são de três espécies: 1) Pausa de não quebra da continuidade do discurso, indicativa de que a frase ainda não foi concluída. Marcam-na: a vírgula, o travessão, os

\footnotetext{
2 Embora o título da obra possa levar a crer que não se trata de uma gramática normativa, a ficha catalográfica a define como tal. Além disso, a organização e o modo de tratamento do conteúdo são similares ao das outras gramáticas consultadas.
} 
parênteses, o ponto e vírgula e os dois pontos; 2) Pausa que indica 0 término do discurso ou de parte dele. Assinalam-na: o ponto simples, o ponto parágrafo e o ponto final; 3) Pausa que serve para frisar uma intenção ou estado emotivo. Mostram-na: o ponto de interrogação, o ponto de exclamação e as reticências.

Cunha e Cintra (2013, p. 657) ressaltam, na Nova gramática do português contemporâneo, que "[...] a língua escrita não dispõe dos inumeráveis recursos rítmicos e melódicos da língua falada. Para suprir esta carência, ou melhor, para reconstituir aproximadamente o movimento vivo da elocução oral, serve-se da PONTUAÇÃO". Os dois estudiosos classificam os sinais de pontuação em dois grupos: aqueles que marcam pausas (sinais pausais) e os que marcam a melodia, a entonação (sinais melódicos).

Percebemos, nas definições expostas, um tratamento da pontuação completamente vinculado à oralidade, especialmente voltado à entonação ou à marcação de pausas.

Em contrapartida, há aqueles que assumem uma posição diferenciada. É o caso de Napoleão Mendes de Almeida que, na Gramática Metódica da Língua Portuguesa (ALMEIDA, 2009, p. 570), define:

[...] segundo a ótima definição de Júlio Ribeiro, pontuação é a 'arte de dividir, por meio de sinais gráficos, as partes do discurso que não têm entre si ligação íntima, e de mostrar do modo mais claro as relações que existem entre essas partes'.

Trata-se de um posicionamento que se aproxima mais de uma concepção sintáticosemântica da função da pontuação, considerando-a do ponto de vista organizacional do discurso, organização que implica clareza dos sentidos construídos.

Faraco, Moura e Maruxo Junior (2010, p. 448) definem a pontuação da seguinte maneira:

[...] sinais de pontuação são símbolos gráficos que empregamos nos textos escritos para organizar os termos, os enunciados e os parágrafos, estabelecendo uma hierarquia (ordem) entre eles. Essa hierarquia sintática torna o texto compreensível.

Novamente, percebemos um posicionamento que atribui à pontuação um papel organizacional, vinculado à lingua escrita, e não à língua falada. 
Bechara define a pontuação retomando Catach (apudBECHARA, 2009, p. 604), estudiosa que apresenta uma concepção mais holística do fenômeno da pontuação:

Com Nina Catach, entendemos pontuação como um "sistema de reforço da escrita, constituído de sinais sintáticos, destinados a organizar as relações e a proporção das partes do discurso e das pausas orais e escritas. Estes sinais também participam de todas as funções da sintaxe, gramaticais, entonacionais e semânticas.

Catach (apud BECHARA, 2009) considera a pontuação como incidente nos níveis linguístico e suprassegmental, isto é, como relativa à oralidade e à escrita.

Diante dessas diferentes posições sobre a função da pontuação, encontra-se uma problemática que dificulta o seu tratamento, como demonstraremos a seguir. Retrocedendo às origens dos sinais de pontuação, é possível perceber os motivos que levaram a essas diferentes concepções.

\section{Dificuldades no tratamento da pontuação}

Muitas pessoas relatam ter dificuldade em usar a pontuação. Essa dificuldade deriva da própria imprecisão que circunda esses sinais, o que se evidencia na afirmação de Rocha (1997, p. 1): "[...] saltam à vista a flutuação e a ambiguidade que cercam o uso desses sinais gráficos".

A flutuação no modo de pontuar apresenta motivos históricos, como nos mostra a estudiosa:

Razões históricas também explicam essa flutuação. Primeiro, o fato de durante séculos a pontuação ter sido um mecanismo optativo e adicional ao texto para facilitar sua leitura, de domínio de uns poucos (leitores e escribas). Segundo, na Idade Média geralmente não era o autor quem escrevia o texto. A natureza morosa e mais artesanal da escrita dessa época possibilitava inúmeras versões de um texto. As tarefas de escrita (composição, cópia e edição) eram divididas entre o autor, o escriba/copista e o editor, que podiam adotar sistemáticas de pontuação diferentes, conforme a orientação do scriptorium onde o manuscrito era produzido. Todos estes fatores eram fonte de divergências (ROCHA, 1998, p. 1).

Além de a pontuação ser facultativa por um longo período e estar vinculada à leitura oral, o fato de o autor do texto (em outros termos, um "escritor" que não tinha 
domínio da escrita) depender de copistas para registrar seus textos e de editores para revisá-los e publicá-los também levava a controvérsias no modo de pontuar.

Para Rocha (1998, p. 4),

há muitos erros de pontuação decorrentes da pressuposição de que existe uma relação unívoca entre a prosódia da fala e a pontuação da escrita, de modo que os usos da linguagem falada possam ser transferidos diretamente para a escrita, sem alterações. Isso é muito comum entre redatores inexperientes.

Um exemplo bastante comum dessa transferência da fala para a escrita ${ }^{3}$ é separar sujeito e predicado por vírgula, como se houvesse uma pausa respiratória entre esses termos, especialmente quando o sujeito é expresso por um sintagma extenso 4 .

Na antiguidade, "[...] as letras eram apenas guardiãs da voz" (ROCHA, 1997, p. 2), e a pontuação, muitas vezes, correspondia à necessidade fisiológica de respirar. Somentena Idade Moderna, entre os séculos XVII e XVIII, o tratamento da pontuação do ponto de vista gramatical passou a ser enfatizado, consolidando-se a ideia de que ela "[...] tinha um papel lógico a desempenhar" (ROCHA, 1997, p.7). Essa visão da função da pontuação deriva do advento da imprensa, no final do século XV e início do XVI, momento em que a escrita ganha autonomia e passa a significar mais que o escrito (grafia, transcrição), liberando-se da fala (ROJO, 2001).

A escrita passa a ser considerada autônoma em relação à fala, deixa de servir, exclusivamente, à oralidade: "[...] malgrado a aparência, o sistema gráfico da língua não é uma mera reprodução do sistema fônico que 'transcreve', mas é, em parte, um sistema semiótico autônomo, dotado de uma gramática própria" (ROCHA, 1997, p. 7).

Mesmo a pontuação tendo adquirido outras funções ao longo da história, muitos usuários da língua ainda se prendem às pausas da oralidade para pontuar, conforme ressalta Rocha (1997, p.12):

\footnotetext{
3 Sobre as relações entre fala e escrita, Biasotto e Buttini (2018).

${ }^{4}$ Quando uma oração se encontra na ordem direta (sujeito - verbo - complemento verbal - adjunto adverbial), dispensa-se o uso de vírgula, tornando-se inadequada a separação entre sujeito e predicado. Em um exemplo como O jovem rapaz do interior do Nordeste não se acostumou com a cidade de São Paulo, o sujeito é constituído por um sintagma extenso (o jovem rapaz do interior do Nordeste), o que pode levar alguns usuários da língua a inserirem uma vírgula entre o sujeito e predicado, caracterizando o uso da pontuação numa perspectiva fonológica, o que estaria incorreto do ponto de vista de uma perspectiva lógico-gramatical (sobre estas perspectivas, ROCHA, 1997).
} 
[...] a este respeito, Catach comprovou, numa enquete realizada com 45 escritores franceses contemporâneos, que a grande maioria se prende à tradição oral da pontuação. Apenas 7 dos entrevistados revelaram seguir uma pontuação gramatical, baseada na sintaxe.

Cabe ressaltar que a enquete foi realizada com escritores que já tinham um elevado grau de domínio sobre a língua e bastante familiaridade com os usos da pontuação. Quando se trata de alunos da educação básica em processo de aprendizagem da escrita, atribuir às pausas para respirar a responsabilidade por determinar os usos da pontuação nos parece um equívoco.

A pontuação pode confundir até os mais experientes escritores, pois cada gênero textual tem um estilo de pontuação diversa. Um exemplo disso, na atualidade, são os gêneros jornalísticos, em que a pontuação é feita de acordo com o foco que se quer dar a determinado assunto. A esse respeito, Rocha (1998, p. 4) ressalta que:

[...] nem sempre a prosódia da fala ou a voz interior que guia o redator coincidem com as prescrições gramaticais, caso em que até mesmo redatores proficientes tropeçam na pontuação [...]. Um mesmo redator precisa ter habilidade para pontuar diferentemente conforme o gênero do texto. Assim, diz Chafe, um publicitário que pontuasse como um professor, em breve perderia o emprego e um professor que o fizesse como um novelista do século XIX, poderia ter seu texto corrigido, dele eliminando-se vírgulas a torto e a direito.

Podemos observar que há, além de uma possível discrepância entre pontuar pela oralidade e pontuar pela escrita, uma discrepância dos usos da pontuação entre os diversos gêneros textuais. Pontuar um romance ou um poema, certamente, é diferente de pontuar um ofício, um artigo científico etc.

É interessante notar a própria contradição encontrada nas gramáticas normativas a respeito da função da pontuação. Dahlet (2002, p. 31) cita gramáticos como Torres, Kury, Barros e Cunha para afirmar que estes "[...] veem na pontuação um meio, ainda que muito imperfeito, de compensar as perdas que a passagem do oral ao escrito produz". A crítica feita pela autora remete ao fato de os gramáticos considerarem a pontuação como um fenômeno de simulação do movimento oral pela escrita, no entanto, assim que começam a exemplificar os usos da pontuação, passam a fazer considerações de cunho exclusivamente gramatical: 
na introdução geral à pontuação, as gramáticas se servem da noção vaga de pausa, atribuindo-lhe uma função vocal. Essa mesma representação é retomada no começo das rubricas: 'A vírgula assinala pausa ligeira, com o tom da voz geralmente em suspenso' (KURY, 1988, p. 65); 'A vírgula marca uma pausa de pequena duração' (CUNHA, 1980, p. 421); 'A vírgula indica a pausa mais fraca' (ALI, 1969, p. 228). Entretanto, assim que os autores começam a exemplificar os empregos desse sinal, o registro passa bruscamente para considerações gramaticais: 'Entre os termos de uma oração, separa quaisquer termos assindéticos de uma função sintática composta' (KURY, 1988, p. 65).

Assim, Dahlet, além de fazer uma crítica às gramáticas tradicionais quanto à verdadeira função da pontuação, defende a necessidade de desvincular oralidade e escrita, sendo necessário "[...] afastar-se do fonografismo, para reintegrar claramente a pontuação em sua área, que é a escrita [...]" (DAHLET, 2002, p.35), e finaliza: "[...] ora, submeter previamente a pontuação a uma dependência estreita do oral leva quase inevitavelmente a aporias, a representações aproximativas, bem como a uma metodologia confusa" (DAHLET, 2002, p. 38).

Parafraseando as ideias de Dahlet (2002), podemos afirmar que as gramáticas tradicionais apresentam métodos imprecisos e ambíguos, que mantém os usuários da língua no desempenho de simples reprodução, levando-os a imitações aproximadas de métodos confusos, sem domínio do que reproduzem. Esta situação de oscilação entre a verdadeira função da pontuação, certamente, reflete-se nas dificuldades de uso adequado dos sinais.

Diante da situação exposta, propomo-nos a verificar, na sequência, quais as funções desempenhadas pelo ponto e vírgula de acordo com algumas gramáticas, verificando se as abordagens encontradas refletem os métodos imprecisos e vagos apontados por Dahlet (2002).

\section{Usos do Ponto e Vírgula de acordo com algumas gramáticas normativas da língua portuguesa}

Neste tópico, faremos uma breve revisão acerca dos usos do ponto e vírgula, a partir do estudo de algumas gramáticas normativas da língua portuguesa. A revisão foi elaborada a partir de consulta às seguintes gramáticas: Curso Prático de Gramática, de Ernani Terra (2011); Moderna Gramática Portuguesa, de Evanildo Bechara (2009); Nova Gramática do Português Contemporâneo, de Celso Cunha e Lindley Cintra (2013); 
Gramática Normativa da Língua Portuguesa, de Carlos Henrique da Rocha Lima (2001) e Gramática Metódica da Língua Portuguesa, de Napoleão Mendes Almeida (2009).

Foram encontradas, reunindo as cinco obras examinadas, sete prescrições de uso para o ponto e vírgula, conforme quadro abaixo:

Quadro 1 - Prescrições gramaticais para o uso do ponto e vírgula

\begin{tabular}{|c|c|}
\hline Prescrição gramatical & Exemplo \\
\hline $\begin{array}{l}\text { 1) para separar orações coordenadas } \\
\text { sindéticas adversativas e } \\
\text { quando apresentarem a conclusivas } \\
\text { posposta ao verbo. }\end{array}$ & $\begin{array}{l}\text { "Você já recebeu mais de uma carta de } \\
\text { seus amigos; deve, portanto, respondê-las } \\
\text { imediatamente" (CEREJA, 1999, p.316). }\end{array}$ \\
\hline $\begin{array}{l}\text { 2) para separar orações coordenadas } \\
\text { sindéticas adversativas que se } \\
\text { contrabalançam em força expressiva } \\
\text { (formando antítese, por exemplo) }\end{array}$ & $\begin{array}{l}\text { "Muitos se esforçam; poucos conseguem" } \\
\text { (TERRA, 2011, p.324). }\end{array}$ \\
\hline $\begin{array}{l}\text { 3) para separar orações coordenadas que } \\
\text { tenham certa extensão }\end{array}$ & $\begin{array}{l}\text { "Não sabe mostrar-se magoada; é toda } \\
\text { perdão e carinho (ASSIS, apud CUNHA e } \\
\text { CINTRA, 2013, p. 666) }\end{array}$ \\
\hline $\begin{array}{l}\text { 4) para separar orações coordenadas que } \\
\text { já venham "quebradas" no seu interior por } \\
\text { vírgula ou num trecho mais longo, onde já } \\
\text { existam vírgulas, para enunciar pausa } \\
\text { mais forte }\end{array}$ & $\begin{array}{l}\text { "Enfim, cheguei-me a Virgília, que estava } \\
\text { sentada, e travei-Ihe da mão; D. Plácida } \\
\text { foi à janela" (ASSIS, } 1899 \text { apud BECHARA, } \\
\text { 2009, p.611) }\end{array}$ \\
\hline $\begin{array}{l}\text { 5) para separar orações, desde que a } \\
\text { segunda contenha zeugma }\end{array}$ & $\begin{array}{l}\text { "Vocês anseiam pela violência; nós, pela } \\
\text { paz" (CEREJA, 1999, p.316). }\end{array}$ \\
\hline $\begin{array}{l}\text { 6) para separar as várias partes distintas } \\
\text { de um período, que se equilibram em valor } \\
\text { e importância }\end{array}$ & $\begin{array}{l}\text { "Sílvio não pede um amor qualquer, } \\
\text { adventício ou anônimo; pede um certo } \\
\text { amor, nomeado e predestinado" (ASSIS, } \\
\text { apud ROCHA LIMA, 2001, p.464) }\end{array}$ \\
\hline
\end{tabular}

Fonte: Elaborado pelas autoras.

A partir do quadro, podemos verificar que, das sete prescrições de uso do ponto e vírgula, seis ( 1 a 6) estão relacionadas à separação de orações e uma relacionada à separação de itens (7). Evidencia-se, assim, a atribuição de uma função de "separação" para este tipo de pontuação. Apenas em 4, menciona-se a função de pausa mais forte, o que corrobora os apontamentos de Dahlet (2002) a respeito dos métodos imprecisos e vagos no tratamento da pontuação. Além disso, algumas funções, além de vagas, são bastante próximas, afinal, todas separam orações. No caso da prescrição 3 (para separar 
orações coordenadas que tenham certa extensão), como se definiria "certa extensão"? A prescrição 4 (para separar orações coordenadas que já venham "quebradas" no seu interior por vírgula ou num trecho mais longo, onde já existam vírgulas, para enunciar pausa mais forte) e a prescrição 5 (para separar orações, desde que a segunda contenha zeugma) se aproximam à medida que ambas se referem à presença de vírgulas nas orações coordenadas. A prescrição 6 (para separar as várias partes distintas de um período, que se equilibram em valor e importância) também gera questionamentos: como medir o valor e importância das partes de um período? Na prática, ao se analisar os exemplos, a distinção entre as funções elencadas torna-se bastante complexa, como demostramos mais adiante.

No próximo item, verificamos, em textos midiáticos, as ocorrências de uso de ponto e vírgula e qual a função que este desempenha nos exemplos encontrados.

\section{O uso do ponto de vírgula na mídia}

Para verificar a hipótese levantada nesta pesquisa sobre o possível desuso do ponto e vírgula na língua portuguesa, optamos por analisar textos contemporâneos escritos por autores de um jornal brasileiro de grande circulação: a Folha de São Paulo. Vejamos como se organizou a coleta e o tratamento dos dados.

Selecionamos, aleatoriamente, quatro colunistas do jornal em questão, na aba "Colunas e blogs": Alexandre Schwartsman (economista), Álvaro Costa e Silva (jornalista), Ana Carolina Amaral (jornalista) e Drauzio Varela (médico). Escolhemos seis textos de cada um dos colunistas, o que nos rendeu um corpus composto por um total de 24 textos. Trata-se, portanto, da seleção de textos escritos por indivíduos proficientes na língua escrita, acostumados com o uso adequado da pontuação.

É preciso destacar que os textos selecionados não pertencem a um único gênero textual, oscilando entre artigos de opinião, crônicas narrativo-argumentativas e reportagens. Assim, guardam em comum o suporte em que circulam e o fato de pertencerem à subseção "blogs e colunas", localizada na seção do jornal denominada "opinião".

A partir dessa escolha, foi feito o levantamento quantitativo de pontos e vírgulas encontrados nos textos analisados, o qual sistematizamos nos quadros abaixo: 
Quadro 2 - Colunista Alexandre Schwartsman

\begin{tabular}{|l|c|}
\hline \multicolumn{1}{|c|}{ Título do texto midiático } & $\begin{array}{c}\text { Quantidade de pontos e vírgulas } \\
\text { encontrados }\end{array}$ \\
\hline $\begin{array}{l}\text { Com reforma, Selic poderá até cair mais; sem ela, o } \\
\text { castigo virá a cavalo }\end{array}$ & 3 \\
\hline O Leopardo no Brasil & 2 \\
\hline $\begin{array}{l}\text { Previdência não 'injeta dinheiro na economia'; como é } \\
\text { hoje, concentra renda }\end{array}$ & 1 \\
\hline $\begin{array}{l}\text { Dólar subiu, juros caíram, e a indústria passou a andar } \\
\text { de lado }\end{array}$ & 1 \\
\hline O que deteve a indústria? & 1 \\
\hline Para cortar a taxa de juros & 10 \\
\hline \multicolumn{1}{|c|}{ Total de ocorrências } & 2 \\
\hline
\end{tabular}

Fonte: Elaborado pelas autoras.

Quadro 3 - Colunista Álvaro Costa e Silva

\begin{tabular}{|l|l|}
\hline \multicolumn{1}{|c|}{ Título do texto midiático } & \multicolumn{1}{|c|}{$\begin{array}{c}\text { Quantidade de pontos e } \\
\text { vírgulas encontrados }\end{array}$} \\
\hline Gatinhos fofos & 12 \\
\hline Olho neles & 0 \\
\hline Os galinhas-verdes & 0 \\
\hline O rio do Rio & 0 \\
\hline O zero-dois & 1 \\
\hline Samurais da dinastia Bolsonaro & 3 \\
\hline Total de ocorrências & 16 \\
\hline
\end{tabular}

Fonte: Elaborado pelas autoras. 
Quadro 4 - Colunista Ana Carolina Amaral

\begin{tabular}{|l|c|}
\hline \multicolumn{1}{|c|}{ Título do texto midiático } & $\begin{array}{c}\text { Quantidade de pontos e } \\
\text { vírgulas encontrados }\end{array}$ \\
\hline $\begin{array}{l}\text { Texto 1: Senador financiado por executivo da mineração } \\
\text { barra CPI mista de Brumadinho }\end{array}$ & 0 \\
\hline $\begin{array}{l}\text { Texto 2: Corretor de seguros dá 'tom perfeito' ao Roda Viva } \\
\text { com ministro do Ambiente }\end{array}$ & 2 \\
\hline $\begin{array}{l}\text { Texto 3: Depois de bloquear ONGs no Twitter, ministro diz } \\
\text { que só quer receber 'ambientalistas sérios' }\end{array}$ & 1 \\
\hline $\begin{array}{l}\text { Texto 4: Governos insistem em afrouxar licenciamento, a } \\
\text { melhor vacina contra desastres ambientais }\end{array}$ & 5 \\
\hline $\begin{array}{l}\text { Texto 5: Novo presidente do ICMBio chama áreas protegidas } \\
\text { de 'propriedades rurais' }\end{array}$ & 0 \\
\hline $\begin{array}{l}\text { Texto 6: China manda indireta para Brasil e EUA em discurso } \\
\text { final na Conferência do Clima }\end{array}$ & 11 \\
\hline Total de ocorrências & \\
\hline
\end{tabular}

Fonte: Elaborado pelas autoras.

Quadro 5 - Colunista Drauzio Varela

\begin{tabular}{|l|c|}
\hline \multicolumn{1}{|c|}{ Título do texto } & $\begin{array}{c}\text { Quantidade de ponto e vírgula } \\
\text { encontrados }\end{array}$ \\
\hline $\begin{array}{l}\text { Texto 1: Mila - Fugiu de casa aos dez, viveu para o trabalho } \\
\text { e a família e hoje sente orgulho }\end{array}$ & 1 \\
\hline $\begin{array}{l}\text { Texto 2: Cadeias e demagogia - A questão prisional é muito } \\
\text { grave para ficar nas mãos de aprendizes de feiticeiro }\end{array}$ & 1 \\
\hline $\begin{array}{l}\text { Texto 3: Solidão universal - Milhares de eventos ao acaso } \\
\text { aconteceram para prover nossa existência }\end{array}$ & 0 \\
\hline $\begin{array}{l}\text { Texto 4: Suicídio assistido - Acabar os dias em estado } \\
\text { vegetal é a derradeira surpresa da condição humana }\end{array}$ & 0 \\
\hline $\begin{array}{l}\text { Texto 5: Criacionismo outra vez - Questionar veracidade da } \\
\text { teoria da origem das espécies, desculpem, é ignorância }\end{array}$ & 0 \\
\hline $\begin{array}{l}\text { Texto 6: Charlatães - Em meio século de trabalho com } \\
\text { pacientes graves, nunca vi um milagre }\end{array}$ & 3 \\
\hline Total de ocorrências & \\
\hline
\end{tabular}

Fonte: Elaborado pelas autoras. 
Com base nos quadros de 2 a 5, percebemos que todos os colunistas selecionados fizeram uso do ponto e vírgula. Schwartsman, Costa e Silva e Amaral utilizaram entre 10 e 16 vezes esse tipo de pontuação, enquanto Varela utilizou apenas 3.

Na sequência, verificamos as funções desempenhadas pelo ponto e vírgula nas ocorrências encontradas nos textos dos colunistas, levando em consideração as sete prescrições gramaticais arroladas no quadro 1. Tarefa um tanto complexa, tendo em vista a imprecisão das recomendações gramaticais, como mencionamos anteriormente.

Quadro 6 - Colunista Alexandre Schwartsman - total de 10 ocorrências

\begin{tabular}{|c|c|}
\hline Ocorrência do ponto e vírgula nos textos & Prescrição gramatical \\
\hline $\begin{array}{l}\text { Texto 1: "Com reforma, Selic poderá até cair mais; sem ela, } \\
\text { o castigo virá a cavalo." }\end{array}$ & $\begin{array}{lrr}\text { 2) para separar } & \text { orações } \\
\text { coordenadas } & \text { sindéticas } \\
\text { adversativas } & \text { que } & \text { se } \\
\text { contrabalançam } & \text { em } & \text { força } \\
\text { expressiva. } & & \end{array}$ \\
\hline $\begin{array}{l}\text { Texto 1: "Já no que se refere ao 'balanço de riscos' ao redor } \\
\text { de suas projeções, o BC ainda manifesta preocupações com } \\
\text { o rumo das reformas no campo fiscal, mas em menor grau } \\
\text { do que no passado recente; por outro lado, admite que } \\
\text { desemprego e capacidade ociosa elevados possam levar a } \\
\text { trajetórias da inflação ainda menores do que as apontadas } \\
\text { por suas projeções." }\end{array}$ & $\begin{array}{l}\text { 6) Para separar as várias partes } \\
\text { distintas de um período, que se } \\
\text { equilibram em valor e } \\
\text { importância. }\end{array}$ \\
\hline $\begin{array}{l}\text { Texto 1: "Caso a nova administração consiga a proeza, } \\
\text { poderá colher os frutos quase imediatamente, na forma de } \\
\text { baixas taxas de juros, abrindo até a possibilidade de nova } \\
\text { redução da Selic; se falhar, porém, o castigo virá a cavalo." }\end{array}$ & $\begin{array}{l}\text { 1) para separar orações } \\
\text { coordenadas } \\
\text { adversativas e condéticas } \\
\text { quando apresentarem a } \\
\text { conjunção posposta ao verbo. }\end{array}$ \\
\hline $\begin{array}{l}\text { Texto 2: "O governo gasta muito e entrega muito pouco. } \\
\text { De acordo com dados do Tesouro Nacional, os três níveis } \\
\text { de governo no país gastaram R } \$ 3,1 \text { trilhões (sem contar } \\
\text { os juros) nos } 12 \text { meses terminados em junho, pouco menos } \\
\text { do que } 40 \% \text { do PIB (Produto Interno Bruto); no fim de } \\
2016 \text {, eram } R \$ 2,9 \text { trilhões, ou } 39 \% \text { do PIB." }\end{array}$ & $\begin{array}{l}\text { 6) Para separar as várias partes } \\
\text { distintas de um período, que se } \\
\text { equilibram em valor e } \\
\text { importância. }\end{array}$ \\
\hline $\begin{array}{l}\text { Texto 2: "A captura do Estado brasileiro por grupos de } \\
\text { interesse não aconteceu nos últimos anos; pelo contrário, } \\
\text { é fenômeno antigo, a ponto de ter sido objeto de } \\
\text { Raymundo Faoro há } 60 \text { anos em seu 'Os Donos do Poder'." }\end{array}$ & $\begin{array}{l}\text { 6) Para separar as várias partes } \\
\text { distintas de um período, que se } \\
\text { equilibram em valor e } \\
\text { importância. }\end{array}$ \\
\hline
\end{tabular}




\begin{tabular}{|c|c|}
\hline $\begin{array}{l}\text { Texto 3: "Previdência não 'injeta dinheiro na economia'; } \\
\text { como é hoje, concentra renda." }\end{array}$ & $\begin{array}{l}\text { 6) Para separar as várias partes } \\
\text { distintas de um período, que se } \\
\text { equilibram em valor e } \\
\text { importância. }\end{array}$ \\
\hline $\begin{array}{l}\text { Texto 3: "A falta de uma abordagem analítica rigorosa } \\
\text { (oriunda da ojeriza à matemática) explica em parte esse } \\
\text { padrão; para entendê-lo plenamente, todavia, não há como } \\
\text { ignorar a agenda política, que primeiro define as } \\
\text { conclusões, para então passar aos argumentos que a } \\
\text { justifiquem." }\end{array}$ & $\begin{array}{l}\text { 1) para separar orações } \\
\text { coordenadas } \\
\text { adversativas e conclusivas } \\
\text { quando apresentarem a } \\
\text { conjunção posposta ao verbo. }\end{array}$ \\
\hline $\begin{array}{l}\text { Texto 4: "Desenhando: num berçário, a idade média ao } \\
\text { morrer mede-se em dias, mas a expectativa de vida é } \\
\text { superior a } 75 \text { anos; a idade média de morte no corte dos } \\
20 \text { aos } 30 \text { anos deve ficar ao redor de } 25 \text { anos, mas a } \\
\text { expectativa de vida atinge } 77 \text { anos." }\end{array}$ & $\begin{array}{l}\text { 3) para separar orações } \\
\text { coordenadas que tenham certa } \\
\text { extensão. }\end{array}$ \\
\hline $\begin{array}{l}\text { Texto 5: "Apesar de o crescimento do PIB no ano passado } \\
\text { ter ficado provavelmente um pouco acima do registrado no } \\
\text { anterior, o desempenho da indústria piorou: em } 2017 \text {, a } \\
\text { produção da indústria de transformação crescera } 2,2 \% \text {; em } \\
2018 \text {, apenas } 1,1 \% \text {." }\end{array}$ & $\begin{array}{l}\text { 5) separar orações, desde que a } \\
\text { segunda contenha zeugma. }\end{array}$ \\
\hline $\begin{array}{l}\text { Texto 6: "Como não há praticamente distinção entre a } \\
\text { evolução esperada do dólar em cada cenário, a diferença } \\
\text { da inflação projetada se deve apenas às premissas distintas } \\
\text { para a Selic ao longo do horizonte: no primeiro cenário a } \\
\text { taxa, como notamos, permaneceria em } 6,5 \% \text { ao ano para } \\
\text { sempre; no segundo começaria a subir no início de } 2019 \\
\text { até atingir } 8 \% \text { ao ano em meados do ano que vem." }\end{array}$ & $\begin{array}{l}\text { 6) Para separar as várias partes } \\
\text { distintas de um período, que se } \\
\text { equilibram em valor e } \\
\text { importância. }\end{array}$ \\
\hline
\end{tabular}

Fonte: Elaborado pelas autoras.

Quadro 7 - Colunista Álvaro Costa e Silva - total de 16 ocorrências

\begin{tabular}{|c|c|}
\hline OCORRÊNCIA DO PONTO E VÍRGULA NOS TEXTOS & FUNÇÃO DO PONTO E VÍRGULA \\
\hline $\begin{array}{l}\text { Texto 1: "Acabou descobrindo uma página que exibe } \\
\text { interminável galeria fotográfica de escritores com seus } \\
\text { felinos de estimação: Bukowski, aparentemente sóbrio, } \\
\text { acariciando com ternura a cabeça do bichano; Guimarães } \\
\text { Rosa segurando dois filhotes no colo; Georges Perec } \\
\text { equilibrando o animal em cima do ombro e roçando a } \\
\text { barbicha no rabo dele; Truman Capote 'cheek to cheek' } \\
\text { com um siamês; Reinaldo Moraes ensinando o pulo da } \\
\text { gata." }\end{array}$ & $\begin{array}{l}\text { 7) para separar os itens de } \\
\text { enunciados enumerativos. }\end{array}$ \\
\hline
\end{tabular}


Texto 1: "Uma coisa leva a outra. Meu amigo adquiriu novo vício. Passou a devorar contos, romances e estudos cujos protagonistas são gatos: 'O Gato de Botas', de Perrault; 'O Gato Preto' de Poe; 'Gato na Chuva', de Hemingway; 'Offenbach', de Cabrera Infante; 'Orientação dos Gatos', de Cortázar; 'Sete Vidas', de Heloisa Seixas; 'Eu Sou Um Gato', de Natsume Soseki; 'As Horas Nuas', de Lygia Fagundes Telles; 'Sobre Gatos', de Doris Lessing."

Texto 5: "Seria normal que os argentinos, para ter o número um, dessem preferência a Messi; e os brasileiros, a Pelé."

Texto 6: "Na ausência do poder público, os donos do pedaço organizam os próprios tribunais; cobram por segurança, transporte, gás, TV a cabo, internet; grilam terras e controlam as construções; matam e mandam matar."
7) para separar os itens de enunciados enumerativos.

5) separar orações, desde que a segunda contenha zeugma.

4) para separar orações coordenadas que já venham "quebradas" no seu interior por vírgula ou num trecho mais longo, onde já existam vírgulas, para enunciar pausa mais forte

Fonte: Elaborado pelas autoras.

Quadro 8 - Colunista Ana Carolina Amaral - total de 11 ocorrências

\begin{tabular}{|c|c|}
\hline Ocorrência do ponto e vírgula nos textos & Função do ponto e vírgula \\
\hline $\begin{array}{l}\text { Texto 2: " 'Apresenta uma apólice de seguro; resolve o } \\
\text { problema da fiscalização', sugeriu um dos entrevistadores } \\
\text { do programa Roda Viva ao ministro do Meio Ambiente, } \\
\text { Ricardo Salles, que ocupou o centro da roda exibida pela } \\
\text { TV Cultura nesta segunda (11)." }\end{array}$ & $\begin{array}{l}\text { 3) para separar orações } \\
\text { coordenadas que tenham certa } \\
\text { extensão. }\end{array}$ \\
\hline $\begin{array}{l}\text { Texto 2: "A bancada de entrevistadores também contou } \\
\text { com a jornalista Cristina Serra, autora do livro Tragédia em } \\
\text { Mariana; a comentarista da rádio Jovem Pan e colunista do } \\
\text { jornal O Estado de S. Paulo, Vera Magalhães; o ex- } \\
\text { secretário estadual do ambiente Xico Graziano e o } \\
\text { ambientalista Carlos Rittl, do Observatório do Clima." }\end{array}$ & $\begin{array}{l}\text { 7) para separar os itens de } \\
\text { enunciados enumerativos. }\end{array}$ \\
\hline $\begin{array}{l}\text { Texto 3: "Questionado sobre qual o seu critério de } \\
\text { seriedade, Salles responde que 'as organizações que } \\
\text { ligarem e agendarem uma reunião para discutir uma pauta } \\
\text { serão recebidas. Mas você não pode ir na internet dizer que } \\
\text { sou burro, incompetente e depois querer vir aqui; isso não } \\
\text { é ter uma boa relação'." }\end{array}$ & $\begin{array}{l}\text { 3) para separar orações } \\
\text { coordenadas que tenham certa } \\
\text { extensão }\end{array}$ \\
\hline
\end{tabular}


Texto 3: "O critério do ministro também inclui regras de comportamento. 'Vou receber quem tenha uma pauta séria; sem assembleísmo, sem manifestação', descreve."

Texto 4: "Tipos de licença:

Única - para obras de baixo impacto ambiental

Trifásica - para obras de alto impacto; consiste em licença prévia, de instalação e de operação."

Texto 5: " 'São 335 fazendas, onde não tem boi, não tem gado; mas algumas que ainda têm', completa Eberhard em seu discurso de posse. Mais à frente na fala, ele volta a usar o termo e busca se justificar. 'Eu nem falo unidades de conservação, que é para dar a dimensão exata do que estamos falando. São 335 propriedades que refletem $9 \%$ do território brasileiro na mão de uma instituição'."

Texto 5: "O fortalecimento continuado da carreira e o aprimoramento técnico do corpo funcional do instituto, incluindo: (i) esforço pela recomposição do quadro de servidores; (ii) proteção e a valorização de todos os servidores, sobretudo os que atuam diretamente em áreas remotas, em regiões de fronteira ou em áreas sob forte pressão de ilícitos; (iii) fortalecimento da política interna de formação e capacitação continuada; (iv) reconhecimento e valorização dos fóruns coletivos e representativos dos servidores, como a Mesa Setorial de Negociação Permanente (MMA), como espaços de consulta e deliberação sobre aspectos inerentes ao desenvolvimento da carreira e; (v) consolidação de uma política transparente e equitativa de remoção interna dos servidores."
7) para separar os itens de enunciados enumerativos.

* Não se enquadra nas sete prescrições encontradas nas gramáticas

3) para separar orações coordenadas que tenham certa extensão.
7) separar os itens de enunciados enumerativos.

Fonte: Elaborado pelas autoras.

Quadro 9 - Colunista Dráuzio Varela - total de 03 ocorrências

\begin{tabular}{|l|l|}
\hline \multicolumn{1}{|c|}{ Ocorrência do ponto e vírgula nos textos } & \multicolumn{1}{|c|}{ Função do ponto e vírgula } \\
\hline $\begin{array}{l}\text { Texto 1: "Alugaram um quarto na rua Helvétia; as } \\
\text { despesas extras pagavam com os furtos que lhe } \\
\text { renderam a primeira das cadeias de poeta, mal } \\
\text { atingida a maioridade". }\end{array}$ & $\begin{array}{l}\text { 4) para separar orações coordenadas } \\
\text { que venham "quebradas" no seu } \\
\text { interior por vírgula ou num trecho mais } \\
\text { longo, onde já existam vírgulas, para } \\
\text { enunciar pausa mais forte }\end{array}$ \\
\hline $\begin{array}{l}\text { Texto 2: "Primeiro, porque na construção das cadeias } \\
\text { de hoje não foram projetados espaços para postos } \\
\text { de trabalho; depois, porque é impossível trabalhar } \\
\text { onde não existe emprego". }\end{array}$ & $\begin{array}{l}\text { 3) para separar orações coordenadas } \\
\text { que tenham certa extensão }\end{array}$ \\
\hline
\end{tabular}


Texto 3: "A atividade vulcânica causou nova extinção em massa, oportunidade aproveitada pelos animais que souberam ocupar os espaços abandonados pelos que se foram; entre eles, os dinossauros e os mamíferos".
5) separar orações, desde que a segunda contenha zeugma

Fonte: Elaborado pelas autoras.

No corpus analisado, composto por 24 textos jornalísticos, encontramos um total de 28 ocorrência do ponto e vírgula. Abaixo, no quadro 10, resumimos as informações dos quadros 6 a 9 quanto às ocorrências encontradas e às funções a elas atribuídas de acordo com as prescrições levantadas nas gramáticas normativas:

Quadro 10 - Quantidade de ocorrências para cada prescrição gramatical

\begin{tabular}{|c|c|}
\hline Prescrição gramatical & $\begin{array}{l}\text { Quantidade de } \\
\text { ocorrências }\end{array}$ \\
\hline $\begin{array}{l}\text { 1) para separar orações coordenadas sindéticas adversativas e } \\
\text { conclusivas quando apresentarem a conjunção posposta ao verbo. }\end{array}$ & 2 \\
\hline $\begin{array}{l}\text { 2) para separar orações coordenadas sindéticas adversativas que se } \\
\text { contrabalançam em força expressiva (formando antítese, por exemplo) }\end{array}$ & 1 \\
\hline 3) para separar orações coordenadas que tenham certa extensão & 5 \\
\hline $\begin{array}{l}\text { 4) para separar orações coordenadas que já venham "quebradas" no } \\
\text { seu interior por vírgula ou num trecho mais longo, onde já existam } \\
\text { vírgulas, para enunciar pausa mais forte }\end{array}$ & 2 \\
\hline 5) para separar orações, desde que a segunda contenha zeugma & 3 \\
\hline $\begin{array}{l}\text { 6) para separar as várias partes distintas de um período, que se } \\
\text { equilibram em valor e importância }\end{array}$ & 5 \\
\hline $\begin{array}{l}\text { 7) para separar os itens de enunciados enumerativos (em leis, } \\
\text { decretos, portarias ou em outros documentos) }\end{array}$ & 5 \\
\hline
\end{tabular}

Fonte: Elaborado pelas autoras.

Como é possível verificar, foram encontradas ocorrências de todas as sete funções elencadas pelas gramáticas normativas consultadas. Os usos que mais apareceram, além da separação de itens de enunciados enumerativos (prescrição 7), foram as prescrições 3 e 6, justamente aquelas que consideramos muito próximas e vagas.

Com base na análise quantitativa dos dados, é possível verificar que todos os colunistas da Folha de São Paulo selecionados para a pesquisa recorreram ao uso do 
ponto e vírgula. Significa dizer que, ao menos nessa esfera da comunicação, esse tipo de pontuação ainda é produtivo.

Cabe destacar que, das 28 ocorrências de ponto e vírgula encontradas no corpus, apenas uma não se enquadrou nas 7 prescrições gramaticais arroladas na pesquisa. Isso pode ser um indício de que os colunistas selecionados pontuam seus textos com base nos usos prescritos gramaticalmente e não baseados apenas em sua subjetividade. Uma outra análise poderia ser feita: os textos passam por criterioso processo de revisão fundamentado no Manual de Redação da Folha de São Paulo, o que os leva a uma padronização no modo de pontuar. No entanto, seria necessário ampliar a pesquisa para obter estas respostas 5 .

Feitas as análises, passemos às considerações finais deste trabalho.

\section{Conclusão}

A relevância da pontuação para a construção dos sentidos dos textos é inquestionável, e seu aprendizado é elementar para o domínio proficiente da escrita. No entanto, as concepções atribuídas a ela nas gramáticas normativas, como pudemos observar, geralmente são vagas e imprecisas, e as prescrições de uso não explicam seu funcionamento, o que não contribui para um uso consciente e autônomo desse recurso.

No trabalho realizado, procuramos responder à pergunta de pesquisa: o ponto $\mathrm{e}$ vírgula encontra-se em desuso na língua portuguesa? Verificamos, a partir dos dados, que a hipótese não se confirmou: esse tipo de pontuação ainda é produtivo para escritores proficientes na esfera comunicativa investigada. Essa constatação abre perspectiva para pesquisas futuras, nas quais se ampliem os corpora, considerando-se diferentes gêneros textuais, faixa-etária dos usuários da escrita, proficiência na língua escrita, entre outros aspectos.

Alguns fatores poderiam justificar a ausência do ponto e vírgula nos textos dos alunos do curso de Letras, o que carece de investigação acurada: a escola tem ensinado os alunos a pontuarem? Os alunos leem suficientemente para aprenderem a pontuar seguindo exemplo de escritores experientes? O ponto e vírgula está sendo substituído por ponto final e por vírgulas nos textos escritos por gerações mais jovens?

\footnotetext{
${ }^{5}$ Esta pesquisa de iniciação científica foi realizada em um período de 12 meses, o que certamente limitou a busca dessas respostas.
} 
Acreditamos que a escola (bem como os materiais didáticos), muitas vezes, negligencia o fenômeno da pontuação e, quando o aborda, assume a perspectiva mais comumente defendida pelas gramáticas normativas: a associação da pontuação à oralidade. Tal fato decorre de outra negligência: o tratamento científico da pontuação. As pesquisas na área, muitas vezes, priorizam traços históricos, descritivos e prescritivos, o que não auxilia os usuários da escrita na compreensão do fenômeno. Além disso, estas pesquisas precisam reverberar nas escolas e nos materiais didáticos, o que nem sempre ocorre ${ }^{6}$.

Para se avançar na compreensão dos usos da pontuação é preciso, de início, atribuir a ela seu verdadeiro papel como um sistema e não apenas como um conjunto cumulativo de regras.

\section{Referências}

ALMEIDA, Napoleão Mendes. Gramática metódica da língua portuguesa. São Paulo: Saraiva, 2009.

BECHARA, Evanildo. Moderna gramática portuguesa. Rio de Janeiro: Nova Fronteira, 2009.

BIASOTTO, Milenne; BUTTINI, Amanda Puglia de Oliveira. Usos da vírgula: diagnóstico de problemas e proposta de soluções. Revista Ecos, Cáceres, v. 25, n. 2, p. 291-321, 2018.

CEREJA, William Roberto. Gramática reflexiva: texto, semântica e interação. São Paulo: Atual, 1999.

CUNHA, Celso; CINTRA, Lindley. Nova gramática do português contemporâneo. Rio de Janeiro: Lexikon, 2013.

DAHLET, Véronique. A pontuação e sua metalinguagem gramatical. Revista Estudos Linguísticos, Belo Horizonte, v. 10, n. 1, p. 29-41, jan./jun. 2002.

FARACO, Carlos Emílio; MOURA, Francisco Marto de; MARUXO JUNIOR, José Hamilton. Gramática. São Paulo: Ática, 2010.

LIMA, Carlos Henrique Rocha. Gramática normativa da língua portuguesa. Rio de Janeiro: José Olympio, 2001.

\footnotetext{
${ }^{6}$ Em trabalho de iniciação científica ainda não publicado, no qual pesquisamos a pontuação em documentos oficiais e livros didáticos referentes ao ensino médio, constatamos que, embora o ensino da pontuação seja mencionado em todos os documentos analisados (Base Nacional Comum Curricular - BNCC, Parâmetros Curriculares Nacionais PCN, entre outros.), as orientações nem sempre são seguidas nos livros didáticos.
} 
ROCHA, Iúta Lerche Vieira. Flutuação no modo de pontuar e estilos de pontuação. Delta, São Paulo, v. 14, n. 1, p. 1-06, fev. 1998.

ROCHA, Iúta Lerche Vieira. O sistema de pontuação na escrita ocidental: uma retrospectiva. Delta, São Paulo, v. 3, n. 1, p. 1-16, fev. 1997.

ROJO, Roxane. Letramento escolar, oralidade e escrita em sala de aula: diferentes modalidades ou gêneros do discurso? In: SIGNORINI, Inês (org.). Investigando a relação oral/escrito e as teorias do letramento. Campinas: Mercado de Letras, 2001. p. 51-74.

TERRA, Ernani. Curso prático de gramática. São Paulo: Scipione, 2011.

Submetido em: 26 jul. 2019. Aceito em: 28 maio 2020. 